\title{
O USO DOS PRONOMES CLÍTICOS DO ESPANHOL EM LIVRO DIDÁTICO DE ENSINO
}

\author{
Chaiane Peruzzo ${ }^{1}$ \\ Gisele Benck de Moraes $^{2}$
}

\begin{abstract}
Resumo: O presente artigo visa analisar um capítulo do livro didático Síntesis com o objetivo de verificar como está sendo desenvolvido, e a partir de que abordagem, o ensino dos pronomes clíticos acusativos do espanhol no Ensino Médio. A base teórica utilizada levou em consideração os preceitos de Spada (1997) e Dutra (2015). A partir dos critérios pretendidos, apresentamos uma análise na qual se averigua a aplicabilidade das atividades propostas no que concerne ao ensino dos clíticos na língua espanhola. Os resultados apontam que o capítulo foca em atividades de classificaçóes e criaçóes de frases isoladas, distantes de um contexto e da autonomia do aluno no processo de aprendizagem.
\end{abstract}

Palavras-chave: Ensino/aprendizagem. Clíticos. Instrução com Foco na Forma.

\section{THE USE OF SPANISH CLITIC PRONOUNS IN AN EDUCATIONAL TEXTBOOK}

\begin{abstract}
A chapter of the textbook entitled Sintesis was analyzed with the aim of assessing how the teaching of Spanish accusative clitic pronouns is being performed in high school, and from which approach. The theoretical framework considered guidelines by Spada (1997) and Dutra (2015). Based on the criteria established, we present an analysis to evaluate the applicability of the activities proposed concerning the teaching of clitics in Spanish. Results show that the chapter focuses on activities of classification and creation of isolated sentences that are distant from context and from the student's autonomy in the learning process.
\end{abstract}

Keywords: Teaching/learning. Clitic. Form-Focused Instruction.

1 Bolsista de Iniciação Científica UPF.

2 Professora Titular II do Curso de Letras da Universidade de Passo Fundo (UPF). 


\section{INTRODUÇÃO}

Este artigo tem como tema o ensino dos pronomes clíticos acusativos do idioma espanhol de terceira pessoa sob uma perspectiva do ensino em livros didáticos. Ao estudar uma segunda língua podemos, por vezes, confundi-la com a língua materna. $O$ português brasileiro e o espanhol são um exemplo disso: por serem línguas próximas, muitas vezes, facilitam o erro e a troca de algumas palavras. A saber, no Português Brasileiro (doravante $\mathrm{PB}$ ) os pronomes clíticos são pronomes pessoais átonos, como: o, a, me, nos, se. Já no Espanhol encontramos me, te, le, $l a(s), l o(s), o s$. Este estudo terá como enfoque apenas os pronomes clíticos acusativos de terceira pessoa da língua espanhola: lo, la, los e las.

A partir do estudo destes pronomes, surge o problema levantado neste artigo: saber como o ensino dos pronomes clíticos de terceira pessoa no espanhol é abordado em livros didáticos e a partir de que viés (descritivo ou normativo) se dá esse processo. Ou seja, pretendemos analisar como se introduz o ensino desses pronomes através de um instrumento muito utilizado pelos professores: o livro didático. Além disso, buscamos verificar a partir de quais gramáticas este ensino está sendo apresentado, bem como constatar quais são as vantagens e desvantagens para o aprendizado do aluno com o modelo de ensino que é escolhido pelo professor. Através da análise da didática utilizada no livro, o objetivo geral deste estudo foi verificar como são apresentados e trabalhados os pronomes acusativos de objeto direto no livro didático de espanhol Síntesis: Curso de Lengua Española, de Ivan Martin. Além disso, i) verificar se o livro didático contempla o ensino dos acusativos em espanhol pelo viés normativo ou descritivo; ii) analisar os tipos de atividades propostas para o ensino dos acusativos (livres, controladas, implícitas e explícitas); iii) observar se a maneira como são apresentados os pronomes permite o desenvolvimento da autonomia por parte do aluno e; iv) averiguar se as atividades propostas para o ensino dos clíticos desenvolvem as quatro habilidades (compreensão leitora, compreensáo auditiva, expressão oral e expressão escrita).

Diante dos objetivos apresentados, é possível afirmar a importância de analisarmos como está sendo introduzido o ensino do espanhol a fim de identificar se as didáticas propostas pelos professores, a partir dos livros didáticos, de fato auxiliam o aluno a compreender de maneira mais fácil e proveitosa o conteúdo, sem que ocorra a transferência para língua materna. Além disso, essa análise também é relevante no sentido de fazer com que os próprios professores avaliem como estáo preparando suas aulas e examinem o livro didático que estão trabalhando. Para tanto, a pesquisa tem como objeto de estudo os pronomes clíticos do espanhol, abordados em um capítulo do livro Síntesis: Curso de Lengua Española, de Ivan Martin, volume três, direcionado aos alunos do ensino médio.

A base teórica deste artigo advém de estudiosos que se dedicam aos pronomes clíticos do espanhol, como Dutra (2015). Para a análise da Instrução com Foco na Forma, usar-se-á Spada (1997), já a análise das gramáticas será feita a partir de Matte Bon (1995) e Llorach (1999). Fundamentado nessas bases teóricas, o artigo foi elaborado como uma pesquisa qualitativa interpretativista. A pesquisa qualitativa 
preocupa-se com a realidade que náo pode ser quantificada; leva em consideração as crenças, os valores. A seu turno, a pesquisa interpretativista é construída pelos seus autores, ou seja, através de pesquisas e relaçóes sociais eles adquirem conhecimento de mundo e, a partir disso, constroem o objeto de pesquisa. $O$ pesquisador aprofunda-se no estudo para ampliar seu conhecimento específico na área estudada a fim de elaborar o seu próprio estudo.

Posto isso, na continuação desta investigação, serão apresentados 0 desenvolvimento, a metodologia utilizada e os resultados obtidos.

\section{A TEORIA DO FOCO NA FORMA}

Esta pesquisa foi feita com base nos estudos da Teoria com Foco na Forma (doravante IFF) cujo conceito visa manter a atenção dos aprendizes nas formas linguísticas e seus sentidos. Sendo assim, a base teórica auxiliou-nos no sentido de buscar perceber de que forma o aluno pode estar aprendendo uma segunda língua, detendo-se à gramática ou também ao sentido da língua em uso.

O responsável por uma das primeiras definiçôes de instruçôes possíveis foi Long (1991). Segundo Moraes (2014), este estudioso definiu que as instruções são divididas em três e que elas variam de acordo com o que é exigido do aluno. Por exemplo, se o intuito é fazer com que o aluno se concentre principalmente no uso da língua, é denominada foco nas formas, mas se o objetivo é que ele se detenha na mensagem comunicativa, designa-se foco no sentido. Já quando a intenção demanda que o aluno se concentre nos dois, na língua e na mensagem que se deseja passar, denomina-se foco na forma. A diferença entre foco nas formas e foco na forma é abordada por Long (1991 apud MORAES, 2014), que exemplifica a ideia de foco nas formas como um conteúdo composto pela linguística que está sendo aprendida, que foca a atenção dos alunos somente na gramática. A seu turno, o foco na forma tenta manter a atenção dos aprendizes ao sentido e à língua, proporcionando ao aluno uma maior significação para o que está aprendendo.

Como vimos, a IFF foca também no sentido e, portanto, deve ocorrer na interação. Logo, necessita ser estudada com atividades que possibilitem não apenas conhecer as regras gramaticais, mas usar a língua comunicativamente e em contextos onde há a presença de um outro, para que ocorra uma interação significativa para o aluno. A IFF refere-se "a qualquer atividade instrucional incidental ou planejada que é destinada a induzir os aprendizes a prestar atenção à forma linguística" (ELLIS, 2001 apud MORAES, 2014, p. 18). Moraes (2014) fraciona a IFF em três tipos: foco nas formas, foco na forma planejado e foco na forma incidental.

O primeiro define-se pelo foco principal na forma linguística, ou seja, o professor conduz o aluno a deter-se na estrutura da língua, em como ela se organiza. $\mathrm{O}$ aprendizado do aluno pode ocorrer de forma implícita, memorizando exemplos e regras; ou explícita, apresentando regras que já se tenha em mente. Neste tipo, como o foco é na forma linguística, o aprendiz receberá estruturas prontas e precisará 
dos seus conhecimentos prévios para entender a atividade e, consequentemente, respondê-la.

O segundo ocorre de forma intensiva, visto que o aluno pode utilizar uma única estrutura já estabelecida pelo professor em inúmeros momentos. Este tipo, planejado e já proposto ao aluno diversas vezes, somente modifica o foco do estudo para que o aluno tenha mais exemplos e aprenda a língua em diversos contextos.

O último tipo, por sua vez, é definido de forma mais ampla, pois procura abranger uma série de formas linguísticas e não ocorre de forma consciente para o aluno. Ele pode ocorrer de duas formas: na primeira o professor utiliza-se de uma problemática para trabalhar, mesmo que os alunos não tenham dificuldades com a estrutura trabalhada; e na segunda a instrução ocorre a partir de um erro linguístico que, então, acarretará o feedback corretivo.

Para mais, salientamos que a Instrução com Foco na Forma prioriza a atenção dos aprendizes no âmbito linguístico e no significado. Ela é vista como um fator de desenvolvimento linguístico, pois permite que os alunos compartilhem de ideias a fim de que, mediados pelo professor, construam o seu próprio conhecimento. Em suma, o foco na forma é "um esforço pedagógico para chamar a atenção do aluno a focalizar a estrutura linguística, seja de maneira implícita ou explícita" (SPADA, 1997 apud MOARES, 2014, p. 18). As açôes pedagógicas implícitas são aquelas em que o professor planejará sua atividade a partir de como ele quer que o aluno corresponda a isso, ou melhor, da maneira que o professor deseja que o aluno pense aquela atividade. Já nas explícitas, o aluno terá em mente as regras, portanto, de forma implícita o aluno memoriza exemplos e assim as regras vão ficando claras para ele.

Posto isso, a IFF "demonstra ser a definição de IFF mais ampla se comparada às outras definiçóes de abordagem instrucional" (SPADA, 1997 apud DUTRA, 2015, p. 61). Dado que a forma náo equivale somente à gramática, mas sim a todo um contexto que está por trás dela e que faz parte da vida do estudante, como o erro ou o grau de complexidade das formas linguísticas. Para mais, a instrução com foco na forma leva em consideraçáo todo o processo de ensino-aprendizagem de um aluno e justamente por isso é considerada a mais ampla: abrange todo o contexto que o aluno deve compreender para que, assim, a gramática faça mais sentido.

Além disso, a IFF pode ser proativa ou reativa. Com base no estudo de Dutra (2015), em que ele retoma a teoria de Spada (1977), considera-se que na proativa, os estudantes focam sua atenção em apenas uma forma pré-selecionada, determinada pelo professor; já na reativa, é possível que o aluno tenha diversas formas de focar sua atençáo. Na primeira, temos uma atividade já planejada, que parte daquilo que o professor deseja que o aluno foque; na segunda, temos vários fatores que podem ser abordados e que surgirão a partir da forma comunicativa, como problemas, erros, dúvidas etc. Sendo assim, ao utilizar a forma reativa extensiva, o professor poderá apenas se utilizar da correção e da didática dedutiva, enquanto a forma proativa e intensiva permite que o professor planeje diversas estratégias pedagógicas, ampliando as oportunidades de demonstrar o conteúdo de formas diferentes, 
podendo tornar o ensino mais atrativo ao aluno. Dessa maneira, é possível observar que a IFF pode auxiliar no aprendizado de uma língua estrangeira.

Segundo o artigo de Gil (2003), para os estudiosos Long (1991) e Gontijo (2000), um aprendizado efetivo da segunda língua ocorre se ele fizer sentido para o aluno. Ou seja, é importante que língua e sentido percorram um mesmo caminho, para que o aprendizado seja mais fácil e mais eficaz. Sobremaneira, o aluno terá mais facilidade em seu aprendizado se o que ele aprende é vivido no seu dia a dia e/ ou se as atividades que o professor propóe fazem sentido. Assim, no momento em que o sujeito-aprendiz precisar usar a língua em um contexto fora da sala de aula, em uma conversa, ele será capaz de utilizá-la de forma correta. Em resumo, é por meio da comunicação defendida por Long (1991) e Gontijo (2000) que o aluno tem a possibilidade de comunicar-se de diferentes formas, imaginando diferentes contextos, não só com o professor, mas também com seus colegas (apud GIL, 2003). Consequentemente, o aluno constrói o seu conhecimento e o professor, enquanto mediador, terá a missão de, com base no diálogo do aluno, acrescentar novos conhecimentos, novas palavras, tornando a aula mais proveitosa.

$\mathrm{Na}$ próxima seção, trataremos de que forma a IFF pode ocorrer, se implícita ou explicitamente.

\section{INSTRUÇÃO COM FOCO NA FORMA IMPLÍCITA $X$ EXPLÍCITA}

A partir da IFF, os aprendizes podem adquirir seus conhecimentos de forma implícita ou explícita. Conforme o artigo de Preuss e Finger (2008), um dos primeiros estudiosos do conhecimento explícito e implícito foi Krashen (1982; 1985; 1994), que os define também como conhecimento aprendido e adquirido. O conhecimento aprendido é consciente, instruído, analisado e refletido, já o adquirido envolve formas subconscientes, ou seja, o aluno obtém o conhecimento sem dar-se conta. No artigo também é destacado que, segundo Krashen (1982 apud PREUSS; FINGER, 2008), o conhecimento implícito ocorre na não consciência do aluno, isto é, ele não é consciente de que houve a aprendizagem e ela só será descoberta quando for demonstrada de forma automática por parte do aluno. Já o conhecimento explícito ocorre de forma consciente para o aprendiz, em outras palavras, ele terá consciência do que está aprendendo independentemente se houver instrução ou não.

Preuss e Finger (2008) destacam que para Krashen (1982) o conhecimento explícito, de certa forma, é mais fácil de ser adquirido, já que o aluno pode comprovar o seu aprendizado através do uso nas atividades solicitadas. Entretanto, o aluno ter o conhecimento internalizado não é garantia de que ele irá utilizá-lo quando necessário. Já Ellis (1994 apud PREUSS; FINGER, 2008, p. 3) afirma que "o conhecimento implícito é operatório, porque apresenta-se no nível da subconsciência e é evidenciado no desempenho do aprendiz". Por sua vez, Ferreira (2001 apud PREUSS; FINGER, 2008, p. 3) menciona que "o conhecimento explícito está sob o domínio da consciência, enquanto o saber implícito opera num nível subconsciente ou náo consciente". De acordo com o exposto, notamos que 
muitos teóricos indagam se existe relaçáo entre os dois conhecimentos e qual é a autonomia de cada um, tanto que se questiona a possibilidade de um saber explícito tornar-se implícito. Tais questionamentos geraram alguns posicionamentos, como a Hipótese da Não Interface, a Hipótese da Interface Forte e a Hipótese da Interface Fraca, a partir dos teóricos Krashen (1985), Sharwood Smith (1994) e Schmidt (1990), respectivamente. Em seu artigo, Preuss e Finger (2008) exemplificam, segundo os teóricos supracitados, cada uma delas.

Para a Hipótese da Não Interface, Krashen (1985) defende que não existe nenhuma relaçáo entre conhecimento implícito e explícito, pois cada um tem sua função em compartimentos diferentes da memória. Com base no artigo, é perceptível que o autor defende a ideia de que ao adquirirmos uma língua temos um processo implícito, subentendido; já ao aprendermos uma segunda língua, isso se dá de forma intencional e explícita, pois adquirir e aprender determinado conhecimento são dois processos distintos no cérebro humano. Sendo assim, ao aprendermos a segunda língua, fazemo-lo de forma intencional, de forma consciente; logo, o ensino deve ser abordado de maneira diferente do modo como seria o de adquirir a primeira língua.

Quanto à Hipótese da Interface Forte, Sharwood Smith (1994) define que a conversão do conhecimento explícito em implícito se dá pela prática linguística, o que torna o conhecimento explícito automatizado. Portanto, segundo ele, pode ocorrer essa transferência do explícito em implícito e ela acontece pela prática linguística. Afinal, quando o conhecimento explícito se torna automatizado, o aluno não tem mais consciência do que está aprendendo, tornando-se, assim, um conhecimento implícito.

Já na Hipótese de Interface Fraca, de acordo com Schmidt (1990), o conhecimento explícito não se transforma em implícito, mas contribui para que isso ocorra quando se possibilita aos aprendizes a percepçáo dos detalhes das formas que estão presentes no input. Sendo assim, não ocorre a transformação, mas ao se ter a língua falada presente na açáo comunicativa (input) o aluno percebe os detalhes presentes nela. Segundo o artigo de Preuss e Finger (2008), Ellis (1993) afirma que este conhecimento - explícito - realiza uma oposição entre os dados recebidos no input e as estruturas do output, fazendo com que o aluno perceba o que está usando adequadamente e o que não.

Seguindo a traduçáo de output como saída, podemos dizer que o aluno, ao realizar o output, poderá colocar em prática o que obteve durante seu input. Ou melhor, como explica Ellis (1993 apud PREUSS; FINGER, 2008), através da "saída" o aluno tem a possibilidade de perceber seus acertos e equívocos ao pôr em prática os conhecimentos adquiridos da língua-alvo. Dessa maneira, o aluno está envolvido de forma completa na aquisiçáo da segunda língua. Também, ao analisarmos como o conhecimento pode ser adquirido - implícita e explicitamente -, é possível relacioná-lo com a aquisição de linguagem, já que tudo passa por um processo, tanto a língua materna quanto a língua estrangeira. 
Em paralelo a isso, Martín (2004 apud ECKERT; FROSI, 2015) apresenta algumas diferenças entre a aquisição da língua materna e a aprendizagem da segunda língua. Primeiramente assinala que a criança que está exposta à língua terá êxito na aquisição do léxico; já na aprendizagem da segunda língua, nem todas as pessoas conseguem ter essa facilidade de aprendizado e, além disso, cada pessoa terá um tempo próprio para familiarizar-se com o novo vocabulário estudado. Em segundo lugar, as crianças usarão o aqui e agora como tempo e espaço, o que, para elas, é o suficiente para seu aprendizado; entretanto, ao estudar uma segunda língua, a aprendizagem será ligada a ideias mais complexas e/ou a estudos mais abrangentes. Outra diferença entre aquisição e aprendizagem é que as crianças não possuem o medo ou a vergonha de errar, costumam falar exatamente como estão pensando, todavia, o adulto possui certo receio em errar e, por isso, evita algumas estruturas que seriam necessárias naquele momento.

Jeremías (2004 apud ECKERT; FROSI, 2015) acredita na hipótese de que a primeira língua é adquirida e as demais precisam ser ensinadas para serem aprendidas. $\mathrm{O}$ estudioso faz algumas consideraçôes que sustentam essa hipótese, por exemplo: a primeira língua é aprendida de forma espontânea e natural, enquanto a segunda língua é aprendida de maneira formal, controlada e baseando-se nas regras. Ademais, salienta que na primeira o aluno é exposto a contextos como jogos, nome de alimentos, brincadeiras, situações que fazem mais sentido para ele, que estáo ligadas ao seu dia a dia; já na segunda língua os contextos de aprendizagem são fatos sobre a aula, relaçóes culturais e situaçóes mais aprofundadas.

Ao analisar essas diferenças entre aquisição e aprendizagem, podemos concluir que ambas exigem do aluno, mas a aquisição da primeira língua torna-se mais natural, ou seja, a criança já está exposta a fatores que a auxiliam nessa aquisição. Em contrapartida, a aprendizagem da segunda língua parece exigir mais do aluno e, por isso, ele possui alguns medos de errar - o que pode afetar a sua aprendizagem -; para ele é necessário usar contextos mais formais, mais ampliados, para que possa aprender de forma mais ampla.

Por ora, salientamos que a base teórica apresentada é importante para esta pesquisa, pois como serão analisadas atividades, é fundamental conhecer de que forma elas podem ser abordadas, refletindo sobre o que pode ser mais proveitoso para o aluno. A seguir, explicaremos sobre os clíticos em espanhol.

\section{DESCRIÇÃO DOS CLÍTICOS}

Nesta seção apresentamos como são estruturados os clíticos em espanhol. Contudo, primeiramente serão analisados os clíticos no Português Brasileiro, a fim de demonstrar as diferenças e semelhanças - caso existam - entre ambos. Após, serão analisados os clíticos no espanhol, sob uma perspectiva normativa e descritiva.

\section{Descriçáo dos clíticos do português brasileiro}

Vejamos o Quadro 1 abaixo: 
Quadro 1 - Clíticos do Português Brasileiro

\begin{tabular}{|l|l|l|l|}
\hline \multirow{2}{*}{ Clíticos } & \multicolumn{3}{c|}{ Não-clíticos } \\
\cline { 2 - 4 } & Nominativo & Acusativo & Oblíquo \\
\hline me & eu & eu & mim \\
\hline te & você (tu) & você & você (ti) \\
\hline o, a, se, lhe & ele, ela & ele, ela & ele, ela, si \\
\hline nos & nós & nós & nós \\
\hline------- & vocês & vocês & vocês \\
\hline os, as, se, lhes & eles, elas & eles, elas & eles, elas \\
\hline
\end{tabular}

Fonte: Silveira (1997, p. 58), adaptado pelas autoras.

Os pronomes ocupam posiçóes argumentais; já os clíticos são núcleos e, justamente por isso, giram em torno do verbo. O PB apresenta um sistema de clíticos menos rico se comparado ao de outras línguas. Para exemplificar isso, conforme a tese de Silveira (1997), Perlmutter (1972) apresenta os clíticos na língua francesa (QUADRO 2):

Quadro 2 - Clíticos do Francês

\begin{tabular}{|l|l|l|l|l|l|l|}
\hline Nom & \multicolumn{1}{|c|}{ Neg } & \multicolumn{1}{c|}{ Refl } & Acusativo & Dativo & Loc & Gen \\
\hline il & ne & me/te/ se nous & le/la/ les & lui/ leur & y & en \\
\hline
\end{tabular}

Fonte: Silveira (1997, p. 58), adaptado pelas autoras.

O francês é composto por clíticos de diversas naturezas como: le, la, lui. Além disso, possui muitos clíticos e pode-se usar mais de um em uma sentença. Assim, Silveira (1997) também exemplifica os clíticos no PB (QUADRO 3):

Quadro 3 - Clíticos do Português Brasileiro

\begin{tabular}{|l|l|l|}
\hline Neg & Clíticos com rima [+e] & Clíticos com rima [-e] \\
\hline náo & me/te/se/lhe $(\mathrm{s}) /$ nos $^{* * \wedge}$ & $\mathrm{o}(\mathrm{s}) / \mathrm{a}(\mathrm{s}) / \mathrm{lo}(\mathrm{s}) / \mathrm{la}(\mathrm{s})$ \\
\hline
\end{tabular}

Fonte: Silveira (1997, p. 60), adaptado pelas autoras.

Conforme conclui Silveira (1997) em sua tese, em relação ao quadro dos clíticos do francês, é possível analisar que o PB se torna mais empobrecido, com menos clíticos, como é o caso dos nominativos, locativos e genitivos, que estáo presentes somente no francês. Analisando o Quadro 3, é perceptível que há uma grande diferença dos clíticos em relação à frequência e a sua colocação. Estáo presentes os clíticos com rima [+e] que correspondem a me/te/se/lhe(s)/nos e os clíticos acusativos de terceira pessoa com rima [-e]. Os clíticos mais usados são os com rima [+e] do primeiro grupo. 
Como mencionado, o francês pode apresentar mais de um clítico em uma sentença, entretanto o PB náo possui essa característica (SILVEIRA, 1997, p. 62):
a. *O livro, o Joáo mo deu ontem
b. *O livro, o João o me deu ontem
c. ${ }^{*}$ O livro, o João o vai me dar amanhã
d. *O livro, o João vai me dá-lo amanhã

Ainda que a ordenação seja distinta, como vemos nos exemplos, não é possível usar dois clíticos em uma mesma sentença. Nos últimos dois exemplos, os clíticos estão em lugares distintos, mesmo assim não está correto.

Os exemplos a seguir mostram que o erro dos anteriormente citados não ocorre por não ser possível a pronominalizaçáo de dois objetos, mas por serem usados dois clíticos em uma mesma sentença. Seguem os exemplos (SILVEIRA, 1997, p. 62):
a. O livro, o João o deu para mim ontem
b. O livro, o João me deu ele ontem
c. O livro, o João o vai dar para mim amanhã
d. O livro, o João vai me dar ele amanhã
e. O livro, o João vai dá-lo para mim

Silveira (1997) conclui que em todos os casos um dos objetos é cliticizado e o outro é pronominalizado. Em (a), (c) e (e) está presente a cliticização do objeto direto e a pronominalização do objeto indireto. Como é possível perceber, no caso (a) temos o clítico o no objeto direto e o pronome oblíquo no objeto indireto (para mim ontem). Em (b) e (d) ocorre o contrário.

Entretanto, pode ocorrer a pronominalizaçáo de dois objetos, uma das peculiaridades do $\mathrm{PB}$, já que os clíticos concorrem com outras formas alternativas, como o pronome tônico e o objeto nulo. Segue o exemplo: "a. O livro, o João deu ele para mim. b. O livro, o João vai dar ele para mim" (SILVEIRA, 1997, p. 63). Outra forma muito utilizada no PB é a forma nula, como é possível verificar no exemplo: "Eu entreguei para a Maria" (SILVEIRA, 1997, p. 64).

Concluindo esta descrição dos clíticos do PB, segundo Silveira (1997), é possível analisar que eles se diferem das outras línguas românicas na cliticização. Além de possuir clíticos diferentes das outras línguas, há também formas alternativas de expressar os objetos que concorrem com os clíticos. Foi possível perceber, também, que em relação à frequência, o clítico [-e] é o que menos ocorre e quando ocorre a sua preferência é pelo lo(s) e la(s). 
O gramático Bechara (2002 apud DUTRA, 2015) explica que para cada forma do caso reto, existe uma forma que corresponda no caso oblíquo. Para exemplificar, as formas retas de terceiras pessoas (singular/plural) ele(s) e ela(s) possuem, como seus correspondentes pronominais, em função objetiva, respectivamente, os pronomes átonos $\mathbf{o}(\mathbf{s}), \mathbf{a}(\mathbf{s})$, se, lhe $(\mathbf{s})$.

Além disso, é possível averiguar, como exemplificado em Dutra (2015), que com o passar do tempo, alguns usos na língua foram mudando. Conforme Castilho (2010 apud DUTRA, 2015), a forma o caiu em desuso pelos falantes do PB, o que ocasionou o ganho de ele e lhe, que funcionavam como sujeito e objeto indireto. Sendo assim, ao invés de ser usado, por exemplo, eu o conheci ontem, usa-se eu conheci ele ontem. No português, também é muito comum o uso da forma nula como variante do pronome clítico. O PB opera com dois grupos de clíticos: me, te, se, lhe(s), nos, em oposição a o(s) e a(s).

É possível perceber que as primeiras e segundas pessoas das formas pronominais podem representar os casos acusativos e dativos. Entretanto, para os pronomes átonos dos clíticos de terceira pessoa não há a equivalência de forma linguística da mesma forma que ocorre nas de primeira e segunda pessoa, já que para as formas de terceira pessoa há somente uma forma linguística para cada caso, gênero e número, como exemplificado anteriormente.

Conhecer os clíticos do PB é fundamental para esta pesquisa, pois além de ser feito um comparativo com os clíticos do espanhol, entendendo as diferenças e semelhanças, será possível localizar nas atividades essas diferenças. Afinal, o aluno aprendiz da língua espanhola tem como base o uso dos pronomes no português; sendo assim, ao realizar as atividades propostas no livro analisado, ele poderá cometer a transferência e, conhecendo mais detalhadamente como são os clíticos em português, saberemos se isso ocorrerá.

A seguir serão apresentados os clíticos no espanhol.

\section{Os clíticos na gramática descritiva do espanhol}

$\mathrm{Na}$ seção anterior observamos os clíticos do $\mathrm{PB}$. A partir de agora serão analisados os exemplos dos clíticos do espanhol na gramática descritiva.

Os pronomes clíticos do espanhol de terceira pessoa da gramática descritiva podem ser mais bem exemplificados a partir da Gramática Comunicativa del Español, de Francisco Matte Bon (1995). O gramático apresenta quatro formas átonas de pronome complemento direto de terceira pessoa, masculino e feminino, singular e plural, apresentadas através do Quadro 4. 
Quadro 4-Pronome complemento direto

\begin{tabular}{|l|l|}
\hline PERSONA A LA QUE CORRESPONDE & $\begin{array}{l}\text { PRONOMBRE COMPLEMENTO DIREC- } \\
\text { TO }\end{array}$ \\
\hline él, usted, (masculino) & Lo \\
\hline ella, usted (feminino) & La \\
\hline ellos, ustedes (masculino) & Los \\
\hline ellas, ustedes (feminino) & Las \\
\hline
\end{tabular}

Fonte: Matte Bon (1995, p. 252), adaptado pelas autoras.

Logo, ele define como exemplo: “a) ¿Y esta lámpara es nueva? Sí, me la regalaron en Navidad” (MATTE BON, 1995, p. 253).

Conforme exemplificado na gramática de Matte Bon (1995), quando há em uma mesma oração vários pronomes complementos é necessário seguir uma ordem, ou seja, deve-se considerar a pessoa a quem se refere cada um deles e a função que está desempenhando na oraçáo. $\mathrm{O}$ pronome se sempre antecede qualquer outro pronome complemento. Quando se juntam dois pronomes de terceira pessoa, o indireto (que vai antes) transforma-se em se: Se lo / se la / se los / se las. Se um desses dois pronomes é reflexivo, sempre precederá ao outro: "a) Por favor, no te me vayas todavia, que necesito hablar contigo. b) ¿Y la lámpara que estaba aqui? Se me cayó esta mañana al limpiarla, y se rompiô" (MATTE BON, 1995, p. 254).

Assim, mesmo quando se junta uma forma átona de pronome complemento com o se da construçáo impessoal, o se sempre precederá: "a) ¡He engordado mucho! Pues no se te nota nada. b) Se te ve cansado. ¿Qué te pasa?" (MATTE BON, 1995, p. 255).

Além disso, as formas átonas de pronome complemento sempre precedem o verbo - se ele estiver conjugado. Về-se em: "a) Me encanta esa camisa. ¿Sí? Me la regalaron el día de mi cumpleaños" (MATTE BON, 1995, p. 255). Entretanto, quando o verbo está no infinitivo, gerúndio ou imperativo afirmativo, os pronomes se pospóem ao verbo, juntando-se a ele: "a) Es difícil ayudarla. No se deja ayudar. b) Pasa, pasa. Siéntate, siéntate” (MATTE BON, 1995, p. 255). A seu turno, no imperativo negativo o pronome vai com qualquer forma conjugada do verbo. A exemplo: “a) No te sientes en esa silla, que está rota” (MATTE BON, 1995, p. 255).

No espanhol, os clíticos acusativos de terceira pessoa também admitem só uma interpretação entre forma e função, diferentemente das primeiras e segundas pessoas em que a forma pode assumir mais de uma função. Como exemplificado por Dutra (2015, p. 26): "Ya pegué la tela = Ya la pegué. / Ya pegué el sello = Ya lo pegué. I Pregunta la hora a María $=$ Pregúntale la hora". Salientamos que os correspondentes das formas átonas no plural, respectivamente, são las, los e les.

As formas átonas também podem estar acompanhadas dos pronomes tônicos ou de um sintagma nominal em caso de duplicação. Exemplificando, "a) Les iba a remitir un regalo a sus nietos. I b) Le llevó la carta a ella” (DUTRA, 2015, p. 
27). A partir disso, é possível averiguar que o pronome clítico está junto com o sintagma nominal. Em b, a duplicação está no uso simultâneo da forma átona com o pronome tônico. Nestes dois exemplos, ocorre a duplicaçáo do caso dativo, isto é, o uso do pronome átono acompanhado de nome, sintagma nominal ou pronome tônico.

Entretanto, existe a possibilidade da coexistência dos pronomes acusativos e dativos. Como no exemplo de Dutra (2015, p. 27): "Le daré un beso a María Se lo darê". Nesta situação, os pronomes clíticos se antepóem ao verbo e a forma correspondente ao pronome clítico em função de dativo de terceira pessoa se converte em se.

A partir do exemplo "Lo vi a él" (él = Felipe), conforme Dutra (2015), é possível analisar que o clítico coexiste com um pronome tônico remetendo a um referente [+humano], o que se faz necessário para que exista a duplicação do clítico de caso acusativo. Com base nos dois exemplos citados a seguir, é possível observar que a presença de um quantificador como todo(s) ou artigo + numeral e de pronome indefinido, são também casos de duplicação de objeto direto: "Los conozco a todos/a los cuatro. I Si la ven a una copiando se ponen furiosos" (DUTRA, 2015, p. 27).

Em alguns casos o clítico pode ser omitido, pois são dativos destinatários, como nos exemplos a seguir. Sendo assim, em caso de duplicação, a partir do papel semântico pode ser obrigatório o uso dos clíticos: "(Le) dijeron a Juan que viniera. I (Le) di el regalo a él' (DUTRA, 2015, p. 27).

No espanhol também é possível a não realização fonética do clítico, como observa-se em: “¿Quieres café? / No, gracias. Ya 《] tomé" (DUTRA, 2015, p. 28). Contudo, Dutra (2015) explica que se café, que é o complemento, fosse substituído por um vaso de café, a resposta teria de ser acompanhada pelo clítico lo. Para o autor, no espanhol, os objetos diretos e indiretos anafóricos são preenchidos com os clíticos acusativos e dativos. E quanto à duplicação, ela é mais regular no caso dativo do que no caso acusativo. No dativo, o uso obrigatório do clítico duplicado está relacionado ao fato de o sintagma complemento náo ser o destinatário; já no acusativo, a partir do traço de especificidade, a duplicação se realiza quando o clítico é correferente com um elemento [+específico].

A partir disso, podemos verificar que o PB apresenta uma maior variedade de possibilidades de realização do objeto direto anafórico, como por exemplo: clítico, forma nula, pronome tônico, repetiçáo do sintagma nominal e lhe. Já o espanhol não apresenta o pronome tônico como possibilidade de realizaçáo do objeto.

Segundo Dutra (2015), em PB o clítico, no que condiz à fala, é a variante menos usada; entretanto, no espanhol, é a predominante. Por sua vez, a forma nula é a variante mais frequente no PB; já no espanhol a forma nula não é tão frequente, mas pode ocorrer como forma de realização do objeto indireto anafórico nos casos em que o antecedente é [-específico] ou [-animado].

Também é possível observar que o $\mathrm{PB}$ e o espanhol apresentam algumas diferenças importantes. Ambas possuem diversas alternativas para a realização do 
objeto direto e indireto anafórico; contudo, no espanhol, os clíticos sáo mais usados do que no PB.

Portanto, por serem línguas próximas e possuírem diferenças significativas, é de extrema importância que se tenha consciência das falsas semelhanças que existem entre as elas. Em outras palavras, espera-se que essa proximidade não conduza a erros e que o aluno tenha consciência de cada peculiaridade.

Por fim, destacamos que apesar de a análise priorizar a forma como são abordados os clíticos no ensino da língua espanhola através do livro didático, conhecer mais detalhadamente seus usos também auxiliará no prosseguimento desta pesquisa.

\section{Os clíticos na gramática normativa do espanhol}

A gramática normativa é baseada em regras e não aceita variações linguísticas, considerando-as erros gramaticais. Alguns gramáticos criticam a normativa, pois já valorizam as outras gramáticas existentes, como a descritiva, apresentada anteriormente.

Em relação aos pronomes clíticos de terceira pessoa, a gramática normativa, segundo Emilio Alarcos Llorach (1999), define que lo e los reproduzem o masculino; la e las o feminino. A unidade lo também serve para a referência de segmentos não marcados pelo gênero, como os chamados neutros e as unidades substantivas complexas substantivadas. Temos como exemplos: Es cuestión de ponerse a ello cuando la necesidad lo exige; cuando te quieras dormir, me lo dices. As unidades le, les e se são indiferentes ao gênero utilizado.

De acordo com Llorach (1999), as funçôes de objeto direto e indireto a que indicam os incrementos pessoais somente estão diferenciadas, ainda que não sempre, pelos de terceira pessoa. Os incrementos de primeira e segunda pessoa (me, te, nos e os) são para ambas funçóes, dado que apontam ao objeto direto em me lavo; te vieron; nos dejaron; os felicitó, ou ao objeto indireto em me lavo las manos; te vieron las intenciones; nos dejaron el coche; os felicitó las pascuas (LLORACH, 1999, p. 200).

O teórico Llorach caracteriza que o incremento lo, entre os de terceira pessoa, emprega-se como referente à função de atributo, em conjunto com o grupo de verbos chamados copulativos (ser, estar, parecer). Nessa função, geralmente aparecem adjetivos e substantivos, os quais, segundo suas possibilidades, podem organizar-se em número e em gênero com os que comportam o substantivo do sujeito explícito, por exemplo: "El niño es altol Las niñas son altas" (LLORACH, 1999, p. 200).

Llorach (1999) exemplifica que, atualmente, se prefere a próclise com as formas verbais utilizadas na ênclise, como "Lo veol La viste". Por outro lado, os substantivos pessoais só se referem a situação em que se fala, e os incrementos pessoais a outras unidades recordadas no contexto linguístico. 
É importante conhecer os clíticos na gramática normativa, para que os critérios da pesquisa sejam analisados de forma coerente, uma vez que será analisado de que forma o livro contempla o ensino dos clíticos, se pelo viés normativo ou descritivo.

\section{O ESTUDO DESENVOLVIDO}

O livro escolhido para a análise é denominado Sintesis: Curso de Lengua Espanhola, de Ivan Martin, Doutor em Letras pela Universidade de São Paulo (USP) e professor da Universidade Federal de São Paulo (Unifesp). Teve sua primeira edição e impressão em 2012 pela editora paulista Ática, é destinado ao Ensino Médio e cada um dos três volumes possui oito capítulos. Na apresentação do livro, é destacada a intenção de despertar no aluno o interesse pelo mundo hispânico e suas variedades culturais.

O capítulo analisado, que se refere aos pronomes complementos, intitula-se "La literatura y la música" e está presente no terceiro volume da série. A Figura 1 demonstra a introdução gramatical da parte em análise.

Figura 1 - Gramática básica: El pronombre complemento

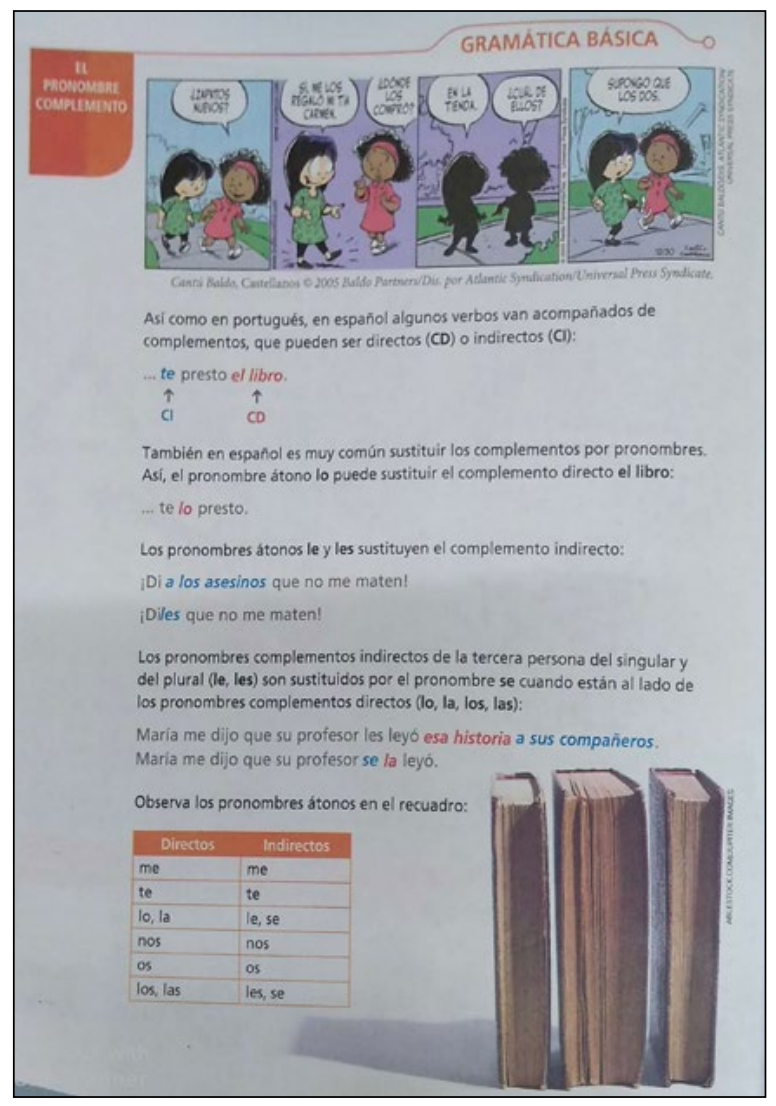

Fonte: Martin (2012, p. 124). 
$\mathrm{Na}$ tira são apresentados alguns pronomes complemento, como: los, lo. É perceptível que a presença dos pronomes ajuda inibir/extinguir a repetição. No primeiro quadrinho surge a pergunta: "¿Zapatos nuevos?", a qual é respondida: "Sí, me los regaló mi tía Carmen". Sendo assim, los regaló está indicando o sapato, termo que não é repetido. Em seguida a menina pergunta: “¿Dónde los compró?”. Mais uma vez, está utilizando o pronome que se refere ao sapato, mas não o repete por uma questão de organização da conversa. A menina responde que comprou na tienda, em seguida a outra pergunta qual deles e recebe a seguinte resposta: "Supongo que los dos". Dessa forma, novamente existe a presença do pronome los que substitui a nomenclatura sapato(s) a fim de promover uma melhor organização frasal e coibir a repetição de palavras.

Posteriormente, são expostas as regras de utilização dos pronomes complementos. É explicado que, assim como no português, no espanhol alguns verbos também váo acompanhados pelo complemento. Podem ser direto (CD) ou indiretos (CI). O livro traz o exemplo (MARTIN, 2012, p. 124):

... te presto el libro.

Exemplo (1)

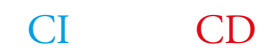

Explica, também, que no espanhol é comum substituir o complemento por pronome. Assim, o pronome átono lo pode substituir o complemento direto el libro (MARTIN, 2012, p. 124).

... te lo presto.

Exemplo (2)

Apresenta que os pronomes átonos le e les substituem o complemento indireto (MARTIN, 2012, p. 124):

Di a los asesinos que no me maten.

Exemplo (3)

Diles que no me maten.

Exemplifica que os pronomes complemento indiretos de terceira pessoa do singular e do plural (le, les) são substituídos pelo pronome se quando estão ao lado dos pronomes complementos diretos (lo, la, los, las) (MARTIN, 2012, p. 124):

María me dijo que su profesor les leyó esa historia a sus compañeros.

Exemplo (4)

María me dijo que su profesor se la leyó.

E indica todos os pronomes átonos através de um recuadro, conforme exposto no Quadro 5 abaixo: 
Quadro 5 - Pronomes átonos

\begin{tabular}{|l|l|}
\hline \multicolumn{1}{|c|}{ Directos } & \multicolumn{2}{c|}{ Indirectos } \\
\hline me & me \\
\hline te & te \\
\hline lo, la & le, se \\
\hline nos & nos \\
\hline os & os \\
\hline lo, las & les, se \\
\hline
\end{tabular}

Fonte: Martin (2012, p. 124), adaptado pelas autoras.

Por fim, o livro apresenta também que ao substituir os complementos diretos e indiretos por pronomes, a ordem da frase é: sujeito + complemento indireto + complemento direto + verbo (MARTIN, 2012, p. 125):

(Yo) Te lo presto.

Exemplo (5)

Ademais, pontua que diferentemente do português, no espanhol se pode começar uma frase com um pronome átono (MARTIN, 2012, p. 125):

¿Lo conoces?

Exemplo (6)

Destacamos que a forma com que o livro Sintesis aborda a gramática, utilizando diferente contextos, pode ser interessante ao aluno. Também vale ressaltar que tira apresentada como introdução ao conteúdo é uma forma importante de o aluno compreendê-lo, pois traz exemplos reais, cotidianos e de fácil entendimento. Outrossim, a tabela explicativa e os exemplos auxiliam o estudante durante a aprendizagem, posto que ele poderá assimilar melhor o conteúdo acerca da separaçáo dos pronomes diretos e indiretos.

Em resumo, é possível dizer que o livro aborda o conteúdo de uma forma acessível, através de tiras, apresentando ao aluno contextos reais em que utilizará os pronomes e indicando de que formas fará isso. Em seguida serão descritos os métodos e critérios de análise.

\section{MÉTODOS E CRITÉRIOS DE ANÁLISE}

O estudo foi feito a partir da análise das atividades propostas no livro Sintesis, levando em consideração toda a base teórica utilizada, como a IFF, as dificuldades de aprender uma segunda língua e tendo em vista que o espanhol é uma língua próxima ao $\mathrm{PB}$ e, por isso, tanto pode auxiliar o aluno quanto pode atrapalhá-lo, já que muitas vezes podem ocorrer transferências indevidas pela (falsa)semelhança entre as duas línguas. Além disso, com base nas gramáticas estudadas, descritiva e normativa, foi feito um levantamento a fim de verificar qual das duas é utilizada no capítulo 
analisado e em que aspecto essa escolha pode auxiliar o aprendiz. O objetivo da pesquisa é contribuir com a aprendizagem dos alunos, consequentemente, analisar se as atividades o ajudam faz parte do processo para que ele, posteriormente, tenha autonomia na língua-alvo e consiga usá-la em todas as situaçôes necessárias.

A análise foi elaborada a partir de uma pesquisa qualitativa-interpretativista, ou seja, é uma pesquisa que trabalha com as relaçôes humanas, com os significados. A saber,

a pesquisa qualitativa responde a questóes muito particulares. Ela se preocupa, nas ciências sociais, com um nível de realidade que não pode ser quantificado. Ou seja, ela trabalha com o universo de significados, motivos, aspiraçôes, crenças, valores e atitudes, o que corresponde a um espaço mais profundo das relaçóes, dos processos e dos fenômenos que náo podem ser reduzidos à operacionalização de variáveis (MINAYO, 2002, p. 21-22).

Já a pesquisa interpretativista é construída pelos seus autores, ou seja, através de pesquisas e relaçóes sociais eles adquirem conhecimento de mundo e a partir disso constroem o objeto de pesquisa. Tem-se, portanto,

como estudos interpretativistas, aqueles que apresentam evidências de uma perspectiva não determinista; na qual a intenção do pesquisador é ampliar seu entendimento sobre o fenômeno em situaçôes contextuais e culturais; onde este é examinado em seu local de ocorrência e a partir das perspectivas dos participantes; e na qual os pesquisadores não impóem a priori seu entendimento de alguém "de fora" da situação (ORLIKOWSKI; BAROUDI, 1991, p. 7).

Quanto ao material objeto de análise, podemos afirmar que o livro apresenta diversas atividades, desde classificaçôes gramaticais até produçôes textuais que incentivam os alunos à escrita, envolvendo as açôes do dia a dia e utilizando a língua-alvo. Além disso,

os volumes do livro Síntesis: Curso de Lengua Española: ensino médio é um material organizado de forma adequada com textos atualizados, apresentando muitas ilustrações que chamam a atenção dos alunos e a gramática é coesa com os textos trabalhados, pois cada capítulo das coleções está organizado em torno de um tema geral, ao qual se relacionam subtemas que visam à formação linguística e cultural dos estudantes (SANTOS, 2012, p. 1).

Os critérios para análise são definidos da seguinte maneira: i) analisar como é abordado o estudo dos pronomes clíticos para alunos da língua espanhola, se abordado pelo viés normativo ou descritivo, averiguando se as atividades facilitam o aprendizado do aluno, estimulando seu conhecimento, além da gramática, de mundo e culturas distintas; ii) verificar se as atividades abordadas são controladas ou livres; iii) descrever se o livro contempla atividades que possibilitem a autonomia do aluno, fazendo com que ele seja capaz de utilizar a língua-alvo em diversas situaçóes do seu cotidiano; e iv) averiguar se as quatros habilidades - compreensão leitora, compreensão auditiva, expressão oral e expressão escrita - são trabalhadas no livro em questấo. 


\section{ANÁLISE DAS ATIVIDADES SELECIONADAS}

Nesta seção serão apresentadas as atividades abordadas pelo livro didático - da maneira que estáo dispostas no material - e a análise pretendida a cada uma delas.

Figura 2 - Atividade 1

Identifica en las frases los complementos directos e indirectos de los verbos:

María leyó la poesía a sus hermanas. CD: la poesía; Cl: a sus hermanas.

a. Ricardo entregó los cuentos a Raúl.

b. Las profesoras enseñaron las fotos a los alumnos.

c. En Brasil, los padres cuentan cuentos a sus hijos.

d. Javier siempre da novelas a su novia.

e. Nadie dijo la verdad a los niños.

Fonte: Martin (2012, p. 125).

$\mathrm{Na}$ atividade número 1, como é possível verificar na Figura 2, percebemos que o aluno necessita indicar nas frases qual é o complemento direto e o complemento indireto dos verbos. Têm-se um exemplo no início da atividade para auxiliá-lo.

Cabe dizer que esta atividade não permite que o aluno tenha muitas alternativas; sendo assim, é uma atividade livre, pois ele precisa responder somente o que se pede, isto é, o que é complemento direto e o que é complemento indireto. Para mais, verificamos que o viés utilizado para o ensino-aprendizagem dos pronomes é normativo, dado que o aluno deve possuir o conhecimento acerca da gramática a fim de aplicá-la na frase em questão. Esta atividade não estimula o aluno a outros saberes além da gramática, pois, como podemos observar, são frases do cotidiano e não frases que trazem informaçôes relevantes a ele. Além disso, não estimula a autonomia, visto que apesar de as frases expressarem acontecimentos do dia a dia, o aluno não é estimulado a pensar nessas ações diárias. Sua função é apenas classificar os complementos, portanto, seu conhecimento acerca das culturas fica limitado. A única habilidade trabalhada é a compreensão leitora, pois o aluno necessita entender a frase para depois identificar nela o que é solicitado pelo enunciado.

Seguindo a base teórica da IFF, conforme Ellis (2001, p. 56 apud MORAES, 2014), ela refere-se "a qualquer atividade instrucional incidental ou planejada que é destinada a induzir os aprendizes a prestar atenção à forma linguística". Logo, é possivel concluir que esta atividade se encaixa em uma atividade proativa, já que é planejada, visto que o estudante foca a sua atenção a somente uma forma, neste caso, a classificar os complementos diretos e indiretos.

Para mais, o aluno não é exposto a uma ação comunicativa, não é instigado à comunicação, somente à escrita. Sendo assim, não contempla a definição de Long (1991) e Gontijo (2000) que consideram a IFF como forma e funçâo dentro de um contexto comunicativo, ou seja, em que o aluno consiga - além de aprender o 
conteúdo - ampliar o seu léxico e desenvolver a habilidade de fala da língua-alvo (apud GIL, 2003).

Portanto, é perceptível, a partir da base teórica, que a atividade não estimula $\mathrm{o}$ ato comunicativo, ou melhor, não desafia o aluno a situaçóes em que ele precise desta habilidade. Em seguida será apresentada a segunda atividade (FIGURA 3).

Figura 3 - Atividade 2

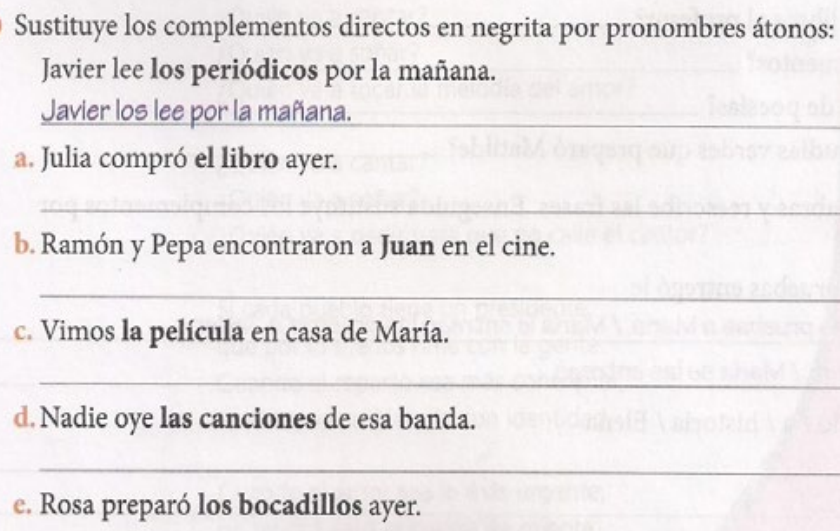

Fonte: Martin (2012, p. 125).

A atividade número 2 solicita aos alunos que substituam o complemento direto por um pronome átono, como podemos observar na Figura 3. Esta questáo é, novamente, abordada pelo viés normativo, pois o aluno necessita saber as regras gramaticais para poder fazer a substituição. Além disso, as frases para a substituição - apesar de tratarem de açóes do cotidiano - estão prontas, isso faz com que o aluno náo desenvolva o aspecto cultural da língua-alvo. A título de exemplo, a frase: "Javier lee los periódicos por la mañana." Nela, o aluno não conhece quem é Javier, não sabe o que estava escrito no periódico, ou seja, ele não entende o contexto, somente se depara com uma frase pronta e que náo possui nenhum sentido para ele. Mesmo assim ele precisa identificar o complemento direto para depois substituí-lo por um pronome átono, logo, seu aprendizado nesta atividade circula apenas no âmbito gramatical.

A tarefa é livre, pois o aluno irá expressar-se e não é possivel controlar de que forma ele fará isso. No entanto, é notável que o aluno tampouco possui autonomia nesta atividade, já que precisa responder o que aprendeu sobre complemento direto e pronomes, náo podendo avançar seu conhecimento para além disso. Por fim, identificamos que são trabalhadas duas habilidades, a de compreensão leitora e a de expressão escrita, visto que o aluno precisa compreender a frase e depois saber expressar-se conforme os aprendizados obtidos.

É uma atividade planejada, logo, proativa. Portanto o professor tem um objetivo ao solicitá-la: o aluno deve saber substituir os complementos por pronomes 
átonos. Entretanto, o que deve ser substituído já está marcado em negrito, ou seja, o aluno não precisa identificá-lo e o professor não saberá se o aluno conhece e/ou identifica o complemento. Isso torna a atividade prática e simples, pois a única funçáo do aluno é substituir o que está em negrito, sem provocar nele o ato de identificar o complemento para depois reescrever a frase.

Evidentemente, o exercício apresentado não segue a IFF, uma vez que não trabalha com o sentido da frase/da estrutura. Seu único e principal foco está na forma linguística, ou seja, na gramática. A Figura 4, disposta a seguir, representa a terceira atividade.

Figura 4 - Atividade 3

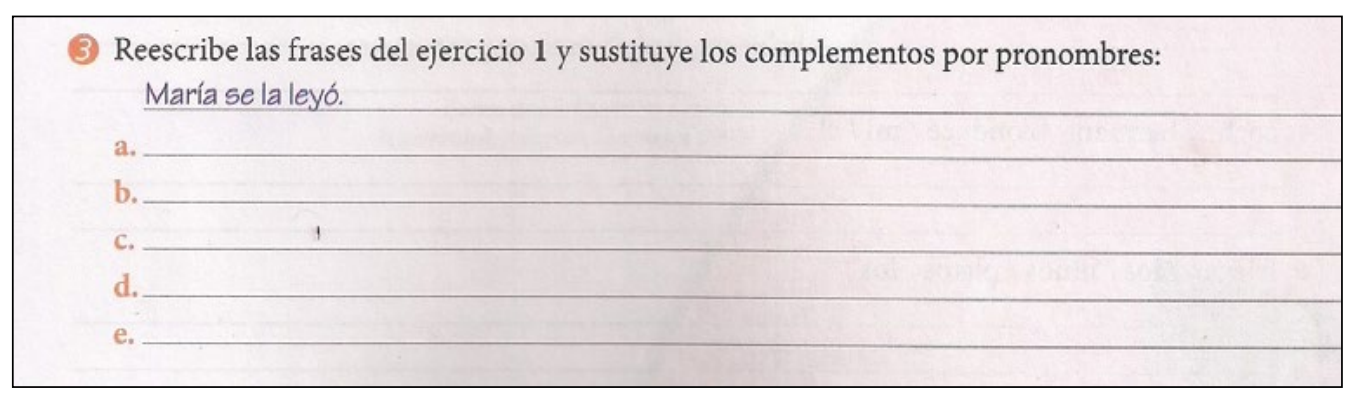

Fonte: Martin (2012, p. 125).

$\mathrm{Na}$ atividade número 3 o aluno deve novamente fazer uma substituição: ele utilizará as frases do primeiro exercício e alterará os complementos por pronomes. O primeiro exemplo do livro traz: "María se la leyó." Sendo assim, está mudando o complemento "la poesia" por "se la", e é isso que o aluno deve fazer em todas as outras frases. Nessa situação, como visto na descrição dos clíticos em espanhol, o pronome clítico está antes do verbo, assim, a forma que a ele corresponde se converte em se.

A atividade, abordada pelo viés normativo, facilita o aprendizado do aluno, pois ele aprende tanto a não usar repetições quanto conhece a forma correta de fazer essas substituiçóes ao escrever e ao falar. Entretanto, novamente são frases prontas que não estimulam sua autonomia e não lhe proporcionam novos conhecimentos. O foco continua sendo apenas gramatical. Para mais, verificamos que se trata de uma atividade livre, pois não é possível ter controle sobre como o aluno substituirá as estruturas e se fará de forma correta. As habilidades trabalhadas nesta atividade são de compreensão leitora e expressáo escrita, o aluno precisa compreender a frase e depois expressar-se corretamente, fazendo a substituição necessária.

Como já visto na base teórica, Long (1991 apud GIL, 2003) exemplifica a ideia de que o foco na forma tenta manter a atenção dos aprendizes ao sentido e à língua, proporcionando ao aluno sentido acerca daquilo que está aprendendo. A IFF oportuniza o ensino da língua-alvo em situaçóes significativas, isto é, em um contexto que gere sentido/significado de aprendizado para o aluno. É patente 
que esta atividade não oportuniza isso, ela simplesmente faz com que ele reescreva frases empregando o uso correto dos pronomes. Além disso, a IFF possui alguns critérios que não são observados nesta tarefa, por exemplo, a ocorrência de uma ação comunicativa. Ela apenas solicita ao aluno que reescreva a frase, não possibilitando a ele um diálogo na língua-alvo e detendo-se apenas aos elementos da língua. A atividade não estimula a autonomia do aluno, pois sua função é reescrever uma frase já pronta ao identificar o complemento e substituí-lo. O dever resume-se, novamente, a somente reescrever frases e fazer substituiçóes.

Logicamente é uma atividade planejada, com intençôes de que o aluno memorize a troca do complemento para o pronome. Entretanto, é de suma importância que o aluno também saiba usar esse aprendizado no diálogo e nas açóes comunicativas do dia a dia. Mas para que isso aconteça, deve-se iniciar o processo em sala de aula. A seguir, apresentamos a quarta atividade (FIGURA 5) e a sua respectiva análise.

Figura 5 - Atividade 4

Lee el cuento, identifica los pronombres átonos y di si son directos o indirectos:

El miedo

Una mañana, nos regalaron un conejo de Indias.

Llegó a casa enjaulado. Al mediodía, le abrimos la puerta de la jaula.

Volvi a casa al anochecer y lo encontré tal como lo había dejado: jaula adentro, pegado a los barrotes, temblando de susto de la libertad.

Eduardo Galeano. Extraido de <poesiacotidiana.tripod.com>. Acceso el 5 de mayo de 2009.

Fonte: Martin (2012, p. 126).

A atividade número 4 abrange os pronomes átonos e a sua classificação (diretos ou indiretos), e sua proposta é normativa, pois o aluno precisa conhecer a gramática para saber o que deverá utilizar. Salientamos, contudo, que ao se trabalhar com um conto, o aluno é exposto a algo além da gramática: conhece um escritor, Eduardo Galeano, é apresentado à forma e à estrutura do gênero e, além disso, amplia o seu vocabulário. Ademais, classifica-se como uma atividade livre, porque o aluno poderá identificar qualquer palavra como pronome, não é possível mediá-lo nessa identificação.

A partir do conto El Miedo, de Eduardo Galeano, o aluno ganha autonomia para identificar estruturas através de um contexto mais amplo, náo apenas por meio de frases soltas que não fazem sentido. Além disso, obtém conhecimentos do cotidiano - de um acontecimento - e isso lhe é significativo. Nesta atividade, o aprendiz deve desenvolver a habilidade de compreensão leitora, pois precisa compreender o conto e, após isso, deverá dizer quais são os pronomes átonos e se são diretos ou indiretos, o que desenvolve nele a expressão oral. É de extrema importância que o aluno se expresse oralmente nesses recortes de situaçóes reais, pois somente assim ele falará cada vez melhor e ampliará seu vocabulário. 
Portanto, concebemos que a IFF seria bem trabalhada, pois o aluno teria o ato comunicativo, mesmo que seja apenas para dizer o que respondeu. É uma atividade simples, que não exige muito do aluno, mas que trabalha com a expressão oral. Todavia, salientamos que ela poderia ser melhor desenvolvida se, ao invés de apenas trabalhar com as classificaçôes, o conto fosse utilizado de outras formas. Por exemplo, seria possível pedir aos alunos qual é o sentido do conto e/ou o que ele quer nos dizer. Assim, promover-se-iam diálogos e ir-se-ia além de meras classificaçôes; trabalhando os aspectos do texto, proporcionar-se-ia uma conversa que certamente faria sentido ao aprendiz e que, além disso, aprimoraria seu vocabulário, mesmo que, às vezes, ele nem perceba as palavras novas que está aprendendo.

O que nos permite comprovar que esta atividade possui IFF é a definiçáo de Long (1991) e Gontijo (2000), que consideram como o Foco na Forma um tipo de "ensino que integra forma e significado dentro de um contexto comunicativo" (LONG, 1991; GONTIJO, 2000 apud GIL, 2003, p. 37). Dito de outra maneira, uma vez que o aluno está exposto às formas gramaticais dentro de um gênero - nesse caso o conto - isso pode proporcionar-lhe novos conhecimentos e uma vivência comunicativa da língua ao ler, interpretar e dialogar com seus colegas sobre o conto. Abaixo, a quinta atividade (FIGURA 6).

Figura 6 - Atividade 5

(5) Contesta a las preguntas:

¿Le has dado flores a María? Sí, se las he dado.

a. ¿Me enseñas la dirección del museo?

b. ¿Le entregaste los libros al profesor?

c. ¿Habéis leído los cuentos?

d. ¿Préstame el libro de poesías?

e. ¿HHan comido las judías verdes que preparó Matilde?

Fonte: Martin (2012, p. 125).

A atividade 5 incentiva o aluno a responder as perguntas, utilizando o pronome adequado a fim de evitar a repetição do complemento. Essa atividade também é abordada pelo viés normativo, exigindo o conhecimento prévio para a sua realização.

Como analisado nos exemplos anteriores, esta também contempla apenas frases soltas. Sendo assim, o aluno não é estimulado a ampliar seu conhecimento, já que as oraçóes não fazem sentido para ele e não trazem nenhum novo aprendizado. E uma atividade livre, pois não é possível controlar de que forma as perguntas feitas serão respondidas. Para mais, trata-se de uma tarefa voltada exclusivamente ao conhecimento gramatical, que não estimula o aluno a novos conhecimentos, apenas exige o entendimento necessário sobre o conteúdo estudado. Ela trabalha com a habilidade de compreensão leitora, porque exige o entendimento da frase com o 
intuito de formular uma resposta, mas o aluno náo é instigado acerca das outras habilidades.

Além disso, verificamos que nesta atividade pode acontecer de o aluno cometer a transferência para a língua materna. A resposta dada no exemplo contém o pronome para repetir: flores (las); entretanto no português a resposta mais comum seria: sim, eu dei, sem o uso do pronome, o que representaria no $\mathrm{PB}$ a forma nula. Neste caso, o aluno, acostumado com os usos do $\mathrm{PB}$, pode náo usar o pronome que retoma a palavra flores e, assim, cometer um erro. Notamos, neste cenário, que a transferência pode não ser positiva para o aluno.

Ademais, o exercício náo é trabalhado o sentido, nem é feito um ato comunicativo, ou seja, não há IFF. Por ser uma atividade simples, de apenas responder à pergunta usando o pronome, novamente só se trabalha o âmbito gramatical, ignorando outros conhecimentos e habilidades que poderiam instigar o aluno; tampouco trabalhou-se a sua autonomia.

Enfim, aparenta ser uma atividade que não apresenta muita diferença no aprendizado, pois só é preciso lembrar qual é o complemento e trocá-lo pelo pronome. Tendo visto isso nas outras atividades, o aluno já faz essa troca automaticamente, sem precisar pensar muito. Portanto, ele não evolui gramaticalmente, nem aprimora o vocabulário, ficando "preso" a classificações com frases que não fazem sentido, das quais ele não se lembrará futuramente. $\mathrm{O}$ livro traz essa atividade, mas o professor, em querendo utilizá-la, poderia ampliá-la. A exemplo, poderia pedir aos alunos para criarem situaçôes com essas frases, situaçóes reais, que ocorrem com eles. $\mathrm{Ou}$, inclusive, conseguiria lograr explicaçóes mais amplas, isto é, as respostas prontas serviriam de base para se chegar a situaçôes que façam sentido e, como consequência, os alunos lembrar-se-iam do que aprenderam.

\section{CONSIDERAÇÓES FINAIS}

Conhecer de que forma estão sendo abordados os pronomes clíticos da língua espanhola é muito importante. Afinal, é a partir da educação básica que os alunos constroem a estrutura necessária para trilharem seus caminhos e, por isso, é válido analisar como está sendo tratado esse ensino, se ele está proporcionando ao aluno autonomia para suas açóes futuras e se este está desenvolvendo as habilidades necessárias para tais intentos. A escolha de analisar os pronomes clíticos se dá pelo fato de existir facilidade em confundir-se com o PB, lembrando que muitos alunos chegam até mesmo a uma licenciatura na área com essa dificuldade.

Percebemos ter analisado com êxito o capítulo sobre os pronomes clíticos, observando atenciosamente cada critério, sempre pensando no melhor para o aluno: o seu aprendizado e a sua capacidade de autonomia - náo somente dentro do espaço escolar, mas também fora dele. Após a análise das atividades, podemos considerar que o desenvolvimento da autonomia poderia ter sido abordado de forma diferente, com mais ênfase, a partir de propostas desafiadoras e não apenas através da solicitaçáo de atividades de substituição. Sabemos que os alunos são extremamente capazes de 
desenvolver seu processo de aprendizagem e de exercitar a capacidade de autonomia em qualquer atividade solicitada pelo professor.

Assim, concordamos com o que pensam Long (1991) e Gontijo (2000), que consideram como o Foco na Forma um tipo de ensino que integra forma e significado dentro de um contexto comunicativo. Contudo, as atividades propostas pouco utilizam a Instruçáo com Foco na Forma, dado que esta procura agregar a língua estudada (gramática) e o sentindo, aliadas ao contexto comunicativo que, por sua vez, permite que o aluno enriqueça seu vocabulário e dialogue com o professor e os colegas; e também evita um foco táo somente em atividades escritas.

Para mais, consideramos poucas as atividades em que o aluno precisa expressarse, precisa conversar com os colegas e até mesmo com o professor sobre as suas açóes diárias a fim de fazer uso do pronome em estudo. Estes diálogos em sala de aula são de suma importância para que o aluno possa, pouco a pouco, desinibir-se ao falar na segunda língua. Cabe ao professor o papel de mediador nesses diálogos, instigando o aluno a falar, bem como introduzindo novo vocabulário, de modo que a aula seja produtiva e proveitosa para todos. Nesse momento, vale ressaltarmos a importância de o professor utilizar outros métodos de ensino para além do livro didático. O livro deve ser um recurso a serviço do professor para o ensino da língua, mas cabe ao mestre ofertar outras oportunidades e possibilidades de aprendizagem para seus alunos.

Nas atividades observadas, a IFF é proativa, pois nota-se, claramente, a intenção do que se quer obter do aluno, do que se quer que ele responda, se ele aprendeu ou não. Nessa classificação, o professor tem como base as atividades e a partir delas sabe o que o aluno deve responder, por mais que náo possa esperar que sua resposta seja a correta, dado que em uma atividade em que o aluno pode responder o que compreendeu, não há como esperar apenas uma resposta, por mais que o professor já a tenha pronta.

Ainda, durante o processo de análise das atividades, pretendemos verificar sob qual viés elas eram feitas, se pelo descritivo ou normativo. Assim, podemos considerar que quase todas se enquadram ao viés normativo, pois exigiam do aluno a forma correta, isto é, a forma padrão do ensino que foi proposto. Ademais, sabemos que o conhecimento, a partir da IFF, pode ser adquirido de forma implícita ou explícita. Nas tarefas propostas, notamos que o conhecimento foi adquirido de forma explícita, já que exige atividades controladas, ou seja, foram criadas possibilidades para que o aluno demonstrasse seu conhecimento através de atividades em que deveria classificar na frase qual era o complemento direto e qual era o complemento indireto; precisaria substituir na frase o complemento por pronome, entre outras.

Ao concluir a análise do capítulo do livro sob todos os critérios pretendidos, é possível dizermos que o livro é uma base para o início do processo de aprendizagem, mas que precisa ser complementado por outros métodos ou atividades. Também, por se tratar de um livro de Ensino Médio, acreditamos que a autonomia dos alunos possa ser mais bem capacitada, inclusive com a possibilidade de que sejam trabalhadas as quatro habilidades: compreensão leitora, compreensão auditiva, expressão oral 
e expressão escrita. Com essas habilidades, o aluno terá condiçóes de desenvolver melhor sua autonomia para a aprendizagem de uma língua estrangeira, bem como poderá focar no uso da língua diretamente de todas as formas.

\section{REFERÊNCIAS}

DUTRA, Eduardo de Oliveira. Os efeitos da instruçáo com foco na forma na aprendizagem dos clíticos de $3^{\circ}$ pessoas do espanhol por universitários brasileiros. 2015. Tese (Doutorado em Linguística Aplicada) - Universidade do Vale do Rio dos Sinos, São Leopoldo, 2015. Disponível em: http://www.repositorio.jesuita.org.br/ bitstream/handle/UNISINOS/5531/Eduardo\%20de\%20Oliveira\%20Dutra\%20_. pdf?sequence=1\&isAllowed=y. Acesso em: 20 set. 2019.

ECKERT, Kleber; FROSI, Vitalina Maria. Aquisição e aprendizagem de línguas estrangeiras: princípios teóricos e conceitos-chave. Domínios de Lingu@gem, Uberlândia, v. 9, n. 1, p. 198-2016, jan./mar. 2015. Disponível em: http://www.seer.ufu. br/index.php/dominiosdelinguagem/article/view/28385/16869. Acesso em: 20 set. 2019.

GIL, Glória. Desenvolvendo mecanismos de foco na forma através da interação na sala de aula de língua estrangeira. The Especialist, São Paulo, v. 24, n. 1, p. 35-55, 2003. Disponível em: https://revistas.pucsp.br/esp/article/view/9413/6983. Acesso em: 10 set. 2019.

LLORACH, Emilio Allarcos. Gramática de la lengua espańola. Real Academia Española. Madrid: Espasa Calpe, 1999.

MARTIN, Ivan. Síntesis: Curso de Lengua Española. São Paulo: Ática, 2012.

MATTE BON, Francisco. Gramática comunicativa del espańol: de la lengua a la idea. Tomo I. Madrid: Edelsa, 1995.

MINAYO, Maria Cecília de Souza (Org.). Pesquisa Social: teoria, método e criatividade. 21. ed. Petrópolis: Vozes, 2002.

MORAES, Gisele Benck de. A aprendizagem do presente do subjuntivo do espanhol por alunos brasileiros: um estudo com foco na forma. 2014. Tese (Doutorado em Linguística Aplicada) - Universidade do Vale do Rio dos Sinos, São Leopoldo, 2014. Disponível em: http://www.repositorio.jesuita.org.br/bitstream/handle/ UNISINOS/3412/Gisele\%20Moraes\%20.pdf?sequence=1\&isAllowed=y. Acesso em: 10 set. 2019.

ORLIKOWSKI, Wanda; BAROUDI Jack J. Studying Information Technology In Organizations: Research Approaches and Assumptions. Information Systems Research, v. 2, n. 1, pp. 1-28, 1991.

PREUSS, Elena Ortiz; FINGER, Ingrid. O papel da instrução explícita na interface entre conhecimento explícito e implícito. Nonada, Porto Alegre, n. 11, p. 111-128, 2008. 
Disponível em: https://lume.ufrgs.br/bitstream/handle/10183/173349/000703628. pdf?sequence=1\&isAllowed=y. Acesso em: 05 set. 2019.

SANTOS, Wellygtton José dos. Análise dos livros didáticos de língua espanhola adotados para o ano de 2012. WebArtigos. [S.l.], 25 nov. 2012. Disponível em: https://www. webartigos.com/artigos/analise-dos-livros-didaticos-de-lingua-espanhola-adotados-para-oano-de-2012/100295. Acesso em: 12 out. 2019.

SILVEIRA, Gessilene. O comportamento sintático dos clíticos no Português

Brasileiro. 1997. Dissertação (Mestrado em Linguística) - Universidade Federal de Santa Catarina, Florianópolis, 1997. Disponível em: https://repositorio.ufsc.br/bitstream/ handle/123456789/112183/110249.pdf?sequence. Acesso em: 08 set. 2019. 